\title{
'Getting out of the dark': Implications of load shedding on healthcare in South Africa and strategies to enhance preparedness
}

Power failures and the lack of a robust contingency plan could prove catastrophic in any healthcare environment, with varied and farreaching consequences. In 2003, a $28 \%$ rise in both accidental and non-accidental deaths was recorded in the USA as a result of mass power outages. ${ }^{[1]}$ For every day with a power outage lasting longer than 2 hours, hospital mortality has been estimated to increase by $43 \%{ }^{[2]}$

In recent times, Eskom, the largest and main provider of electricity in South Africa (SA), has not always been able to meet the electrical demands of the country, implementing various stages of power outages dubbed 'load shedding. ${ }^{[3]}$ Lack of maintenance of existing power stations, failure to successfully introduce new infrastructure, poor management and allegations of corruption are some of the suggested reasons. ${ }^{[4]}$

SA already has a strained healthcare system, largely owing to inefficient financial management, a disparity in the distribution of resources and a quadruple burden of disease. ${ }^{[5]}$ In a 2017 survey of 19 developing countries, SA was ranked last on efficiency in healthcarerelated expenditure. ${ }^{[6]}$

More than $80 \%$ of South Africans are reliant on public healthcare services. ${ }^{[7]}$ There are approximately 420 state-run hospitals and more than 3000 state-run clinics across SA. ${ }^{[7]}$ While private facilities and secondary- and tertiary-level public hospitals appear to be well equipped with generator banks, ${ }^{[8]}$ smaller healthcare facilities including primary healthcare clinics are often left in the dark. ${ }^{[9,10]}$ The cost of alternative sources of power can be substantial. Recently, a private hospital group reported an average monthly expenditure of ZAR800 000 to run its generators. ${ }^{[1]}$

\section{Increased load on healthcare services}

Approximately half of South Africans live below the upper-bound poverty line and therefore lack the financial resources to obtain safer alternatives to electrical power. ${ }^{[12]}$ The use of unsafe alternative sources of energy such as paraffin, gas, petrol, wood and plastic may potentially increase the risk of carbon monoxide and cyanide poisoning as well as burn-related injuries. ${ }^{[13,14]}$ An increase in emergency medical services (EMS) use by more than $50 \%$ as well as longer scene times have been reported during disaster-related power outages. ${ }^{[6]}$ Similarly, increases in emergency department visits ${ }^{[15,16]}$ and hospital admissions have been noted during power outages. ${ }^{[2,17]}$

\section{Hygiene and infection control}

According to the General Household Survey, electricity is used by $76.8 \%$ of South Africans to cook food. ${ }^{[18]}$ Load shedding may potentially increase the risk of foodborne diseases for a variety of reasons, from dirty utensils to food not being kept fresh. ${ }^{[19]}$

The maintenance of sewage and running water systems is vital for healthcare facilities to ensure adequate infection prevention. SA's sewage and water systems are known to be poorly maintained and already struggle to meet the demands of public sanitation and water requirements. ${ }^{[20]}$ When load shedding occurs, these systems become further dysfunctional. In the case of a prolonged power failure, reservoirs may even run dry. ${ }^{[9,14]}$

In addition, during load shedding staff may not be able to sterilise surgical instruments and other essential items, thereby potentially delaying emergency interventions and increasing the risk of complications. ${ }^{[21]}$ Ultraviolet light sources, which are useful for reducing the presence of resilient microbes in critical care areas, may also be dysfunctional during periods of load shedding. ${ }^{[22]}$

\section{Light and temperature control}

A well-lit environment is of paramount importance to any medical facility. According to the regulations pertaining to private healthcare facilities, hospitals are required to provide lighting in maternity delivery rooms, operating rooms, ward corridors and critical care areas during power failures ${ }^{[23]}$ Currently there is no legal requirement for healthcare facilities to provide backup power for maintaining thermal regulation. ${ }^{[23]}$ Temperature control during power failures presents a unique challenge in the healthcare industry. ${ }^{[13,14]}$ Excessively high temperatures have been associated with an increase in the proliferation and spread of infection, whereas excessively low temperatures may induce hypothermia and hypocoagulability. ${ }^{[24]}$

\section{Cold storage}

Various medications, vaccines and blood products need to be stored within specific temperature ranges. ${ }^{[25,26]}$ The efficacy and safety of these products may be compromised during prolonged and unpredictable power outages. ${ }^{[27]}$ Erratic temperatures in hospital mortuaries may accelerate the decomposition of corpses, which may potentially compromise postmortem examination, delay the burial of the deceased and potentially increase the risk of spread of infection. ${ }^{[28]}$

\section{Equipment}

Tertiary hospitals provide care for a large number of critically ill and injured patients, who often require the use of multiple electronic devices. ${ }^{[29]}$ Although most critical devices have built-in back-up battery power, they are subject to various limitations that include a limited duration of power supply. Should these devices fail, healthcare staff may be required to intervene manually, thereby decreasing the availability of staff for other essential duties. Although portable oxygen cylinders can be used when the central oxygen supply system is dysfunctional during power outages, such contingencies would be likely to fail during prolonged periods of power loss and ultimately affect patient outcomes. ${ }^{[14,30,31]}$ In addition, non-function of hospital elevators during load shedding can severely restrict the movement of patients and staff. ${ }^{[14,27]}$

\section{Diagnostic services}

There have been reports of complete loss of radiological and pathological services during instances of natural disasters and extreme weather events as a result of power outages. ${ }^{[27]}$ Although these services may be fully functional at larger facilities with adequate back-up power supply, ${ }^{[32]}$ smaller facilities with inadequate power back-up would be unable to provide them, necessitating transfer of patients to larger facilities and further burdening both the EMS and the receiving hospital. ${ }^{[27]}$

\section{Communication and administrative services}

The loss of communication during power outages presents a great challenge. This includes but is not limited to an inability to 
Table 1. Summary of recommendations to enhance preparedness for load shedding

- Installing uninterruptable power supply (UPS) technology to run computers, label printers, fridges, blood gas analysers, etc

- Storage and maintenance of fully charged back-up batteries for essential devices

- Limit opening of fridge doors during power outages

- Stocking of an adequate supply of non-perishable foods

- Load-shedding roster to activate additional clinical and administrative staff when required

- Point-of-care ultrasound and laboratory testing as an alternative to formal radiology and laboratory services

- Stringent maintenance and oversight of generators and back-up devices

- Connecting of sensitive and life-sustaining medical devices to red electrical power outlets that are capable of automatically switching between municipal and emergency generator power circuits

- Adequate fuel reserves at hand, with due consideration to cost and shelf-life ( 6 - 12 months)

- Implementation of alternative energy sources (wind, solar)

- Consideration of biomimicry architecture and multi-storey ramps when designing new facilities

- Implementation of load-shedding action plans and regular drills to test back-up power sources

- Government intervention to limit power outages at healthcare facilities

- Storage of additional oxygen cylinders with regulators, bag-valve-mask resuscitators, oxygen tubing, portable pulse oximeters, manual sphygmomanometers and additional blankets per high-dependency bed

- Establishing of community-based shelters where technology-dependent patients are able to access adequate power supply for continuation of medical care

recharge cellular phones, inadequate network signals and loss of internal electrically dependent telephonic systems. Patients, family members and other members of the public may be unable to communicate with the affected hospital or clinic. Inside the hospital, communication between wards, staff members and departments will also be compromised, which could cause significant delays in relaying pertinent information. ${ }^{[1,33]}$ Many hospital pharmacies use electronic scripting and dispensary systems to provide and issue medications to patients and healthcare staff. ${ }^{[34]}$ Although contingencies may be in place for the manual dispensing of medications, this may increase the time taken to process medication prescriptions, thereby causing major backlogs.

\section{Financial and psychological implications}

Prolonged or frequent loss of basic services, including power outages, has been shown to precipitate the onset of several mental health conditions such as depression, anxiety and post-traumatic stress disorder, ${ }^{[14]}$ which may add further strain to local mental health services. Staff morale plays an important role in the execution of professional duties, particularly among those employed in the healthcare industry. ${ }^{[35]}$ Healthcare workers are not immune to the psychological implications of load shedding.

\section{Suggested measures to enhance load- shedding preparedness}

Although at the time of writing there had recently been a decrease in load-shedding episodes, analysts indicated that load shedding was expected to return soon. ${ }^{[36]}$ Healthcare facilities and related services, in conjunction with the National Department of Health, need to implement various contingency measures and strategies. Suggested strategies are summarised in Table 1.

\author{
A E Laher, B J van Aardt, A D Craythorne, M van Welie, \\ D M Malinga, S Madi \\ Department of Emergency Medicine, Faculty of Health Sciences, \\ University of the Witwatersrand, Johannesburg, South Africa \\ abdullahlaher@msn.com
}

1. Anderson GB, Bell ML. Lights out: Impact of the August 2003 power outage on mortality in New York, NY. Epidemiology 2012;23(2):189-193. https://doi.org/10.1097/EDE.0b013e318245c61c

2. Apenteng BA, Opoku ST, Ansong D, Akowuah EA, Afriyie-Gyawu E The effect of power outages on in-facility mortality in healthcare facilities: Evidence from Ghana. Glob Public Health 2018;13(5):545555. https://doi.org/10.1080/17441692.2016.1217031

3. Pollet BG, Staffell I, Adamson K-A. Current energy landscape in the Republic of South Africa. Int J Pollet BG, Staffell I, Adamson K-A. Current energy landscape in the Republic of South
Hydrogen Energy 2015;40(46):16685-16701. https://doi.org/10.1016/j.ijhydene.2015.09.141

Hydrogen Energy 2015;40(46):16685-16701. https://doi.org/10.1016/j.ijhydene.2015.09.141
4. Niselow T. Sunday Read: Load shedding through the years and how Eskom has struggled to keep the lights on. Fin24, 24 March 2019. https://www.fin24.com/Economy/Eskom/sunday-read-loadshedding-through-the-years-and-how-eskom-has-struggled-to-keep-the-lights-on-20190324 (accessed 26 June 2019).

5. Pooja Y. South Africa’s quadruple burden of disease. Open Health News, 28 March 2015. http://www. openhealthnews.com/story/2015-03-28/south-africass-quadruple-burden-disease (accessed 27 June 2019).

6. Groenewald Y. South Africa last in healthcare efficiency study. Fin24, 9 June 2017. https://www.fin24. com/Economy/south-africa-last-in-healthcare-efficiency-study-20170609 (accessed 24 June 2019). . Statistics South Africa. Public healthcare: How much per person? 2 October 2017. http://www.statssa. gov.za/?p=10548 (accessed 29 June 2019).

8. Mkize V. 90 seconds between life and death. City Press, 18 February 2019. https://city-press.news24. com/News/90-seconds-between-life-and-death-20190216 (accessed 2 July 2019).

9. Modise K. Concerns raised as power cuts impact Gauteng hospitals. Eyewitness News, 2019. https:// . Modise K. Concerns raised as power cuts impact Gauteng hospitals. Eyewitness News, 2019. https://,
ewn.co.za/2019/02/17/concerns-raised-as-power-cuts-impact-gauteng-hospitals (accessed 3 July 2019).

10. Mandiwana N. Load shedding deaths: Answers wanted on Faith's death. Capricorn Voice, 24 June 2015. https://capricornreview.co.za/52055/answers-wanted-on-faiths-death/ (accessed 2 July 2019).

11. De Wet P. Load shedding could end up costing Netcare more than R1 million a month. Business Insider South Africa, 28 March 2019. https://www.businessinsider.co.za/netcare-load-sheddingexpenses-for-hospital-generators-2019-3 (accessed 2 July 2019).

12. Statistics South Africa. National Poverty Lines 2018. Statistical release P0310.1. Pretoria: Stats SA, 2018. http://www.statssa.gov.za/publications/P03101/P031012018.pdf (accessed 29 July 2019).

13. Ismail A. The health dangers of load shedding. Health24, 3 February 2015. https://www.health24.com/ News/Public-Health/How-load-shedding-can-kill-you-20150203 (accessed 21 July 2019).

14. Klinger C, Landeg O, Murray V. Power outages, extreme events and health: A systematic review of the literature from 2011 - 2012. PLoS Curr 2014;6:1-23. https://doi.org/10.1371/currents.dis.04ebldc5e7 3dd1377e05a10e9edde673

15. Dominianni C, Lane K, Johnson S, Ito K, Matte T. Health impacts of citywide and localized power outages in New York City. Environ Health Perspect 2018;126(6):067003. https://doi.org/10.1289/ EHP2154

16. Gehringer C, Rode H, Schomaker M. The effect of electrical load shedding on pediatric hospital admissions in South Africa. Epidemiology 2018;29(6):841-847. https://doi.org/10.1097/ EDE. 0000000000000905

17. Lin S, Fletcher BA, Luo M, Chinery R, Hwang S-A. Health impact in New York City during the northeastern blackout of 2003. Public Health Rep 2011;126(3):384-393. https://doi. org/10.1177/003335491112600312

18. Statistics South Africa. General Household Survey 2018. 28 May 2019. http://www.statssa.gov.za/ publications/P0318/P03182018.pdf (accessed 23 July 2019).

19. Sithole Z, Juru T, Chonzi P, et al. Food borne illness amongst health care workers, at a Central Hospital, Harare, Zimbabwe, 2016: A retrospective cohort study. BMC Res Notes 2017;10(1):715. https://doi. org/10.1186/s13104-017-3030-x

20. BIO Sewage Systems. Four facts about sewage treatment in South Africa you should know. 2019. http:// www.biosewagesa.co.za/article/four-facts-about-sewage-treatment-in-south-africa-you-shouldknow/ (accessed 18 July 2019).

21. McGain F, Moore G, Black J. Steam sterilisation's energy and water footprint. Aust Health Rev 2017;41(1):26-32. https://doi.org/10.1071/AH15142

22. Netcare. Netcare teams up with germ-zapping robots to take the war on 'superbugs' to a new level. News, 24 November 2017. https://www.netcare.co.za/News-Hub/Articles/ArticleId/616/netcare-teams-upwith-germ-zapping-robots-to-take-the-war-on-superbugs-to-a-new-level (accessed 6 July 2019).

23. KwaZulu-Natal Department of Health. R158 - regulation governing patient care facilities. 5 November 1996. http://www.kznhealth.gov.za/R158.pdf (accessed 7 August 2019).

24. Kaafarani HMA, Velmahos GC. Damage control resuscitation in trauma. Scand J Surg 2014;103(2):8188. https://doi.org/10.1177/1457496914524388 
25. Hatchett $R$. The medicines refrigerator and the importance of the cold chain in the safe storage of medicines. Nurs Stand 2017;32(6):53-63. https://doi.org/10.7748/ns.2017.e10960

26. Khoza S. Blood stock critically low: SANBS. SABC News, 8 November 2017. http://www.sabcnews com/sabcnews/national-blood-stock-critically-low-sanbs/ (accessed 2 July 2019).

. The impact of the 2003 blackout on a let earned and implications for injury prevention. J

28. IUSS online. Hospital Mortuary Services. 30 June 2014. https://www.iussonline.co.za/docman/ document/support-services/98-hospital-mortuary-services-gazetted/file (accessed 14 August 2019). Madi S, Motara F, Enyuma C, Laher AE. Audit of defibrillators at an urban public sector hospital. Heart Asia 2018;10(2). https://doi.org/10.1136/heartasia-2018-011065

0. Health24. Load shedding killed my baby. 10 February 2015. https://www.health24.com/News/Public Health/Load-shedding-killed-my-baby-20141124 (accessed 19 August 2019).

31. Katz D. Hospital power outages may lead to lawsuits. FindLaw, 6 November 2012. https://blogs. findlaw. com/injured/2012/11/hospital-power-outages-may-lead-to-lawsuits.html (accessed 18 July 2019).

32. Kumar RK. Technology and healthcare costs. Ann Pediatr Cardiol 2011;4(1):84-86. https://doi. org/10.4103\%2F0974-2069.79634
33. De Villiers J. This is what will happen to your cellphone signal if load shedding drags on. Busines Insider South Africa, 13 February 2019. https://www.businessinsider.co.za/south-africa-cellularnetwork-signal-during-loadshedding-vodacom-mtn-2019-2 (accessed 17 July 2019).

34. Porterfield A, Engelbert K, Coustasse A. Electronic prescribing: Improving the efficiency and accurac of prescribing in the ambulatory care setting. Perspect Health Inf Manag 2014;11. https://www.ncbi nlm.nih.gov/pmc/articles/PMC3995494/ (accessed 29 August 2019).

35. Manyisa ZM, van Aswegen EJ. Factors affecting working conditions in public hospitals: A literature review. Int J Africa Nurs Sci 2017;6:28-38. https://doi.org/10.1016/j.ijans.2017.02.002

36. Head T. Eskom: Another expert explains why load shedding 'will return in August'. The South African 30 July 2019. https://www.thesouthafrican.com/news/eskom-load-shedding-before-august-why/ (accessed 05 August 2019).

S Afr Med J 2019;109(12):899-901. https://doi.org/10.7196/SAMJ.2019.v109i12.14322 